To the Editors:

\title{
A case of POEMS syndrome with mixed hyaline vascular and plasma cell type Castleman's disease
}

(Index words: POEMS syndrome, Castleman's disease, non-Hodgkin's lymphoma, plasmacytoma)

\begin{abstract}
We report a 43-year old man who developed progressive ascending sensorimotor polyneuropathy, a solitary bone plasmacytoma originating from a rib and an axillary lymph node with features of Castleman's disease, mixed hyaline vascular and plasma cell type. He was diagnosed of having non-Hodgkin's lymphoma seven years back and was treated. Examination revealed a smooth goitre, thickened skin, white nails, small testes and ankle oedema. Investigations revealed a monoclonal para-proteinaemia of $7.83 \mathrm{~g} / \mathrm{l}$ and elevated levels of serum TSH and prolactin. In this case the Castleman's disease is localised and the lymphoma preceded the Castleman's disease.
\end{abstract}

\section{Introduction}

Occurrence of polyneuropathy, organomegaly, endocrinopathy, monoclonal gammopathy and skin changes (POEMS) is a rare paraneoplastic syndrome associated with a plasma cell-proliferative disorder. The association between POEMS syndrome and Castleman's disease is well recognised and the latter is considered a major criterion for diagnosis of POEMS syndrome [1].

\section{Case report}

A 43-year old man presented with progressive numbness and weakness of all four limbs of ten weeks duration, a lump in the left anterior chest and a left axillary lymph node for ten months. He was on treatment for diabetes mellitus for 8 years with good glycaemic control. Seven years back he was treated for non-Hodgkin's lymphoma - diffuse large B-cell, immunoblastic type. On examination he had thick skin over the hands and whitish nails. A smooth goitre, testicular atrophy and bilateral pitting ankle oedema were also noted. Bilateral symmetrical distal muscle weakness of all four limbs with areflexia and stocking type sensory loss were seen. He did not have hepatosplenomegaly, ascites or pleural effusion.

Investigations revealed a platelet count of $720 \times 10^{9} / 1$ and a monoclonal gamma band (paraprotein level of 7.83 $\mathrm{g} / \mathrm{l}$ ) comprising of elevated IgG. Nerve conduction studies showed evidence of sensorimotor polyneuropathy affecting all four limbs with demyelinating features. The cerebrospinal fluid protein level was $120 \mathrm{mg} / \mathrm{dl}$. Chest radiograph demonstrated a mixed osteosclerotic and osteolytic lesion in the left 4th rib anteriorly. The rest of the skeletal survey and bone marrow trephine biopsy were normal. A biopsy from the subcutaneous tissue over the mass on the left anterior chest wall (Figure1) showed features of a plasmacytoma. Histology of the axillary lymph node suggested Castleman's disease, mixed hyaline vascular and plasma cell type (Figure 2 and 3 ). Hormonal studies revealed normal testosterone and LH levels with marginally high FSH level and elevated levels of TSH and prolactin. Fasting blood sugar was $6.7 \mathrm{mmol} / \mathrm{l}$. Tests for ESR, serum calcium, HIV, hepatitis $\mathrm{B}$ and $\mathrm{C}, \mathrm{VDRL}$ and urinary Bence Jones protein were negative. A diagnosis of POEMS syndrome was made and the patient was started on local radiotherapy.

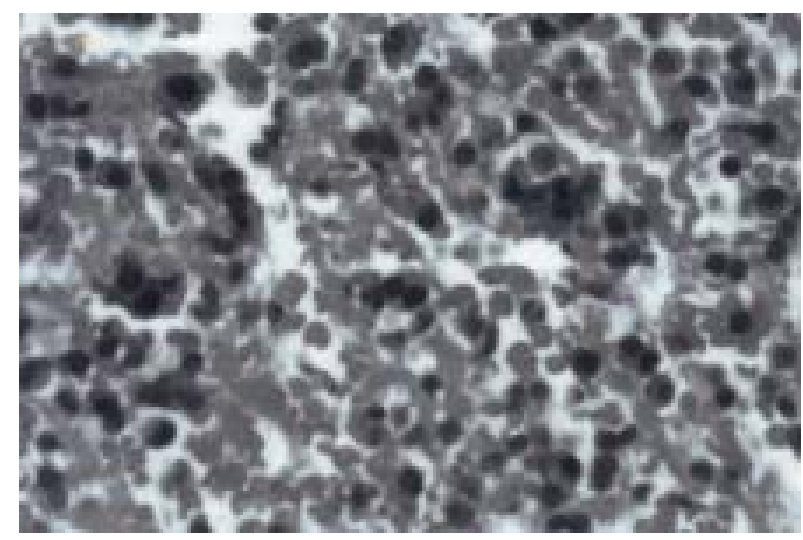

Figure 1. A photomicrograph of the subcutaneous tissue over the cystic mass, showing features of a plasmacytoma with a large number of mature and immature plasma cells (Hematoxylin-eosin $\times 10$ ).

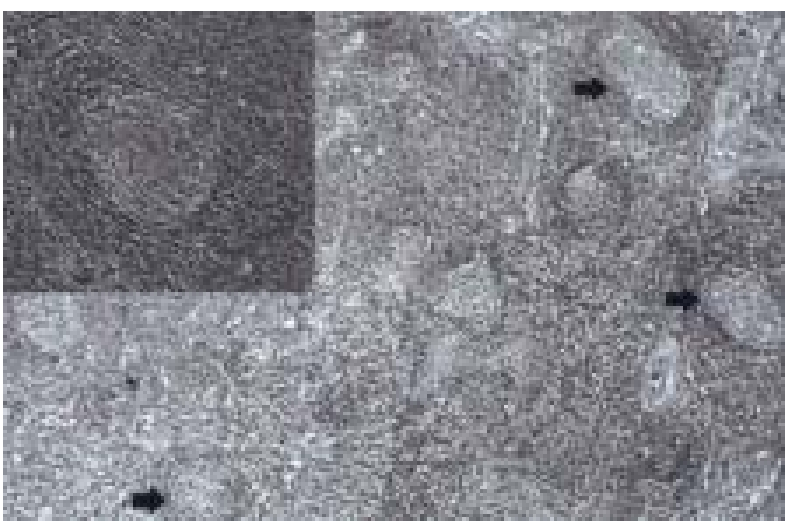

Figure 2. A histological section of the axillary lymph node from an area showing features of hyaline vascular Castleman's disease. Lymph node architecture is partially effaced with follicle like structures (block arrows) (Hematoxylin-eosin $\times 10$ ).

Inset: An enlarged view of a follicle like structures with central vascular proliferation surrounded by multiplied mantle zone lymphocytes arranged in concentric layers. (Onion skin appearance) (Hematoxylin-eosin × 40). 


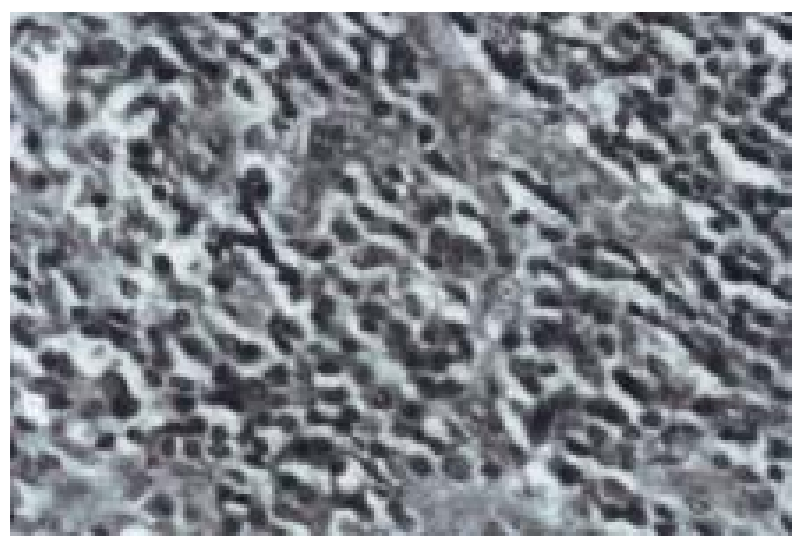

Figure 3. A histological section of the axillary lymph node from an area showing Castleman's disease plasma cell type features with sheets of plasma cells clustered in the paracortex (Hematoxylin-eosin $\times 10$ ).

\section{Discussion}

Patients with POEMS syndrome present with a wide range of clinical features. To link these features, diagnostic criteria have been proposed [2] and revised [1]. In our patient the diagnosis was established by four major criteria (polyneuropathy, plasmacytoma, a sclerotic bone lesion, and Castleman's disease) and five minor criteria (lymphadenopathy, ankle oedema, skin thickening and white nails, endocrinopathy and thrombocytosis). Only three major criteria and one minor criterion are essential for the diagnosis.

Castleman's disease is found in $11-60 \%$ of patients with POEMS syndrome [2]. However, it is the multicentric Castleman's disease that is known to be associated with POEMS syndrome [3] not the localised Castleman's disease as in our patient. Lymphomas are known to occur concurrently or subsequently to Castleman's disease [4]. To the best of our knowledge it has not been reported to precede Castleman's disease. However, Castleman-like changes can occur in lymph nodes in patients with malignant lymphomas [4].

\section{References}

1. Dispenzieri A. POEMS syndrome. Blood Reviews 2007; 21: 285-99.

2. Dispenzieri A, Kyle RA, Lacy MQ, et al. POEMS syndrome: definitions and long-term outcome. Blood 2003; 101: 2496-506.

3. Shahidi H, Myers JL, Kvale PA. Castleman's Disease. Mayo Clinic Proceedings 1995; 70: 969-77.

4. Mauch PM. Non-Hodgkin's lymphomas. 1st Ed. New York: Lippincott Williams \& Wilkins, 2003.

\section{K P Ruwan C Parakramawansha ${ }^{1}$, I Wijeweera ${ }^{1}$, Neelakanthi Ratnatunga ${ }^{2}$ and W G V Sumanasekara ${ }^{1}$}

${ }^{1}$ Neurology Unit, Teaching Hospital, Kandy, Sri Lanka and ${ }^{2}$ Department of Pathology, University of Peradeniya, Sri Lanka.

Correspondence: KPRCP, e-mail: <ruwan@med.ruh.ac.lk>. Received 2 June 2008 and accepted 10 January 2009. Competing interests: none declared. 